\title{
The Use of Contraceptives in Nigeria: Benefits, Challenges and Probable Solutions
}

\author{
Iseoluwa Titilayo Aina*1 Adetutu Deborah Aina-Pelemo ${ }^{2}$ \\ 1.Department of Law, Afe Babalola University, Ado-Ekiti, Ekiti State, Nigeria \\ 2.Department of Law, Sharda University, Greater-Noida, Uttar-Pradesh, India
}

\begin{abstract}
This work examines the decision-making processes among couples, and explained the benefit, challenges and probable solutions to the use of contraception in Nigeria. This work is predicated on the premise that contraceptive decision-making is a complex process that involves an array of factors and structural forces that operate and intersect at different levels to influence decision-making on one hand and the dearth of legal framework to regulate the proper and correct use of contraceptives in Nigerian Reproductive Health Law on the other hand. The use of doctrinal research was employed by sourcing materials from internet, journals, and textbooks as well as statutory laws. This paper found that making informed choices on the methods of contraception posed a huge challenge which is a direct consequence of lack of quality contraceptive services or sufficient access to health facilities, misinformation and a dire absence of knowledge in some instances. This paper concluded that in order to make improvements to women's reproductive lives, the society should have health awareness on the use of contraceptives and its benefits and promulgate a robust, comprehensive and specific regulation for the controlled use of contraceptives in Nigeria.
\end{abstract}

Keywords: Contraceptives, Benefits, Prospects, Challenges, Solutions, Reproductive Health, Nigeria.

DOI: $10.7176 / J L P G / 86-09$

Publication date:June $30^{\text {th }} 2019$

\section{Introduction}

Contraceptive use is a key factor in preventing unwanted pregnancies (Alano \& Hanson 2018; Shukla et al. 2017), reducing maternal and child mortality as well as improving the lives of women and their families (Cleland et al. 2012). A recent study estimated that contraceptive use could avert more than two-fifths of maternal deaths (Ahmed et al. 2012). Increased access to contraceptive services has been established as a cost-effective strategy for countries to reduce maternal and child mortality (Moreland \& Talbird 2006). The benefits of contraceptive use go beyond the health sector. Providing unrestricted access to contraceptives will help ensure a reduction in unwanted pregnancies and thereby contribute to increased female education, women's empowerment, poverty reduction and even environmental sustainability (Moreland \& Talbird 2006).

The benefits of oral contraceptives to women is enormous, it does not only reduce morbidity and mortality caused by pelvic infection, gynecologic cancers, and harms related to menstrual cycle, but also increase bone density and treat emerging acne indications (Jensen \& Speroff 2001; Tyrer 1999). It was reported that the risk of ovarian and endometrial malignancy, as well as ectopic pregnancy is reduced by $90 \%$ in Oral contraceptive users compared with women not using contraceptive pills (Dayal \& Barnhart 2002; Drife, 1991). In a study conducted among two groups of patient, it was revealed that the use of contraceptive pills is recommended as pre-treatment for patients with endometriosis before ovarian stimulation, as it proffers advantages of lesser cost and enhanced embryo-quality, and does not influence pregnancy rates negatively when compared with those patients who do not undergo oral contraceptive pre-treatment (Chakrabartty et al. 2017). Oral Contraceptives pill is used to reduce several health risks and improve several ailments in women (Fagbamigbe et al. 2018), to mention a few; colorectal cancer, endometriosis, menorrhagia, ovarian cysts, rheumatoid arthritis, uterine leiomyomas, pelvic inflammatory disease, uterine fibroids, dysmenorrhea, premenstrual syndrome etc. (Jin 2014; Schindler 2013; Johannes et al. 2008; Dayal \& Barnhart 2002). As much as oral contraceptives has numerous health benefits, it could also pose as a disadvantage to the society and wellbeings in several ways, for examples; it encourages premarital sexual intercourse and thereby tarnish the societal religion and moral standard. It may cause clotting disorders in women (Goldstuck \& Kluge 2017), behavioural changes (Batres et al. 2018), long term usage can cause hormonal imbalance which may lead to severe complications, such as; brain malfunction, cervical or breast cancer, thrombosis and infertility (Shukla et al. 2017).

However, when the advantages and disadvantages of oral contraceptive use are placed side by side, the advantages out weighs the risks involved (Dayal \& Barnhart 2002). Meanwhile, knowledge and awareness of the benefits of oral contraceptive use is in controversy among most women. In a survey conducted among (2544) Two thousand, five hundred and forty-four European and American participants, 98\% admitted awareness and current usage of contraceptive pills (Johnson et al. 2013). This shows a high rate of awareness among the participants. Similarly, mapped out researches found that $95.2 \%$ of $800,66.8 \%$ of 1,200 and $84 \%$ of 500 respective participants have high knowledge of contraceptives usage among Nigerian Universities female 
students (Bankole \& Onasote, 2017; Bello et al. 2016; Eniojukan et al. 2015), still there is no reduction in population growth and social problems attached. Is it that the participants are knowledgeable of the oral contraceptive pills but refused to use them? Or they do not have a clear understanding of the importance of contraceptive use.

\title{
2 Aim of the Paper
}

The primary objective of this paper is to provide a brief overview of what contraception entails, discuss key determinants affecting knowledge and use of contraceptives, identify possible pitfalls arising from the unregulated use of contraceptives in Nigeria and explore best practices for overcoming the barriers of lack of knowledge, and wrong use.

\section{Research Methodology}

The authors adopted secondary source of research methodology in discussing this review paper. It involves doctrinal research, that is; traditional study of legal propositions associated to contraceptive use in Nigeria, coupled with other information from internet, journals, textbooks, academic websites, and conference proceedings. Similar method was adopted by researchers in discussing their review study (Aina-Pelemo \& Saluja, 2018; Aina-Pelemo et al. 2018; Tsui et al. 2010).

\begin{abstract}
4 Discussions
Contraception can be defined as a procedure or device which prevents fertilization of the egg or the implantation of the fertilized egg (R (Smeaton) v Secretary of State for Health 2002). It can also be defined as family planning or advanced technology invented to overcome biology in such a way that it controls fertility (Idoko et al. 2018; Adegbola \& Habeebu-Adeyemi 2016; Hubacher \& Trussell 2015). The fact that women feel obliged to possess the control over their own bodies and as such, make use of contraceptives with or without their partner's consent through self-medication as encouraged by the counter sale of contraceptives makes the situation more worrisome, especially since there is a dearth of effective laws and policies guiding the use, sale and authorization of the proliferation of contraceptives in Nigeria. This paper therefore attempts a theorizing on the use and abuse, challenges, prospects and solutions to the improper and unregulated use of contraceptives in Nigeria.
\end{abstract}

\section{Law Regulating the Use of Contraceptive in Nigeria}

Hall et al. (2010) emphasised on the misuse of contraception among women. It has been widely contended that there is no specific comprehensive law in Nigeria that explicitly regulates the sale or use of contraceptive drugs and devices (Ladan 2006). However, the National Policy on Population states that: "national family planning programme shall provide variety of methods of fertility regulation to ensure free and conscious choice for all couples and contraception distribution is legal in Nigeria (National Demographic Survey 2013; Peterson et al. 2013). Besides, there is no law prohibiting the advertising of contraceptive information. Sterilization is legal in Nigeria if the purpose is to save life, or for contraceptive purposes (Ladan 2006). Notwithstanding the fact that there seems to be no single, robust and comprehensive legislation saddled with regulating the administration of the use of contraceptives, fertility and birth control in Nigeria, there are a spec of scattered provisions that seek to achieve quality reproductive and sexual health for all Nigerians and they include:

- $\quad$ Rule 23, Code of Medical Ethics in Nigeria;

- Constitution of the Federal Republic of Nigeria 1999 as amended section 17, 33 to 45; (Uzoukwu v Ezeonu 1991) ${ }^{1}$

- $\quad$ Section 54 and 55 of the Labour Act; ${ }^{2}$

- National Policy Health Policy and Strategy 2004;

- $\quad$ National Policy on Women 2004;

- $\quad$ National Policy on Maternal and Child Health 1994;

- National Policy on Population for Development, Unity, Progress and Self-reliance 2004

- National Policy on HIV/AIDS.

There are other State Legislations that aim to achieve a similar objective and they include (Uzoma 2016);

- The Enugu State Prohibition of Infringement of a Widow's and Widower's Fundamental Rights Law 2001

- Cross Rivers State Girl-child Marriage and Female Circumcision (Prohibition) Law 2000

- Edo State Female Genital Mutilation Prohibition Law

- $\quad$ Bauchi State Hawking by Children (Prohibition) Act 1985.

\footnotetext{
${ }^{1}$ Right to Life and Health Reproductive Health, Right to Dignity of Human Persons, Right to Privacy and determining the number and spacing of children, Right to Equity and Non Discrimination.

${ }^{2}$ Cap. L1 LFN 2004.
} 


\section{Knowledge of Contraceptive Methods}

Study reveals that majority of the women $(83 \%)$ are aware of condom as a contraceptive method and this was quickly followed by pills (64\%), IUD (48) and injectables (46\%) (Nsubuga et al. 2016). Other notable methods are abstinence (34\%) and withdrawal $(26 \%)$. The information indicates that very few women are aware of implants (9\%) and emergency contraceptive (8) spermicides (5\%) (World Health Organisation 2018a).

Knowledge of contraception, employment status and age were equally held to be good predictors of women's contraceptive use while level of education and number of children were deemed not to be (World Health Organisation 2018a). Knowledge of contraception was a significant predictor of women's contraceptive use (Fayehun 2017). Report from Alan Guttman Institute supports the view that women are likely to use contraception because contraceptive information is available (Guttmacher 1981). Though some women were aware of different types of contraception, very few uses or were aware of modern methods due to early marriages and low level of literacy in some parts of Nigeria (Wang \& Cao 2019; Babalola et al. 2015).

Although the levels of contraceptive knowledge are high (Bankole \& Onasote 2017; Eniojukan et al. 2015), and usage is higher among older women when compared with women who married at the age of 18 (Bello et al. 2016). This indicates that age is of great importance in women's use of contraceptives. Higher contraceptive use was associated with higher educational level because selection of contraceptive method is determined by the level of education and social exposure of the women (Inal et al. 2017). Hence, level education has a significant role to play in the use of contraceptives. Greater knowledge about contraception was found among women with a secondary or higher education, among women with three or more surviving children and among urban women (Narzary 2009) as compared to the $63.8 \%$ of 291 Cross-river State, rural women who rarely use contraceptive or engage in family planning due to religious beliefs, reduction of sexual pleasure, culture, need of children, lack of belief in family planning, and that it promotes infidelity (Etokidem et al. 2017). This clearly indicates the absence of comprehensive importance or benefits of contraceptive use in that region.

\section{Use of Contraceptives}

Contraceptives are devices, drugs, or methods for preventing pregnancy, either by preventing the fertilization of the female egg by the male sperm or by preventing implantation of the fertilized egg (Idoko et al. 2018). Contraception stands as the morally most acceptable form of fertility control that possibly attracts less criticism when compared to that which depends on destruction of embryos (Mason et al. 2013).

The staggering rate of teenage pregnancies, unwanted pregnancies and other health issues arising from lack of birth control reveals an urgent need for reproductive health information especially as it relates to birth control measures (Demographic \& Health Survey NPC 2014). It is pertinent to note that Nigeria has the highest fertility/morbidity level in Africa (Wang \& Cao 2019). Lack of adequate knowledge of birth control methods impact negatively on the use of contraceptives and this consequently leads to high rate of miscarriages, unsafe abortion, stillbirths, unwanted children and a reduction in employment prospect for women (Wang \& Cao 2019; Fagbamigbe et al. 2018; Fayehun, 2017). Other complications such as infant or maternal deaths might also occur. It is in this guise and wise that legal attention must be directed to the prompt and effective regulation of Contraceptive use in Nigeria.

There are several methods of promoting and regulating contraception. This involves both short and long term methods (Etokidem et al. 2017).

Short-term methods e.g. condoms, pills and Long term methods e.g. implants and IUCD- (Intrauterine Contraceptive Device)

1. Hormonal contraceptive

- Hormonal contraceptives are considered convenient and effective methods of spacing children - or even not having children at all. Examples are;

- Combined oral contraceptives (COCs); Ordinary pills; Progestin-only contraceptive pills (POPs); Injectable contraceptives; contraceptive implants (Jadelle, Implanon)

- Hormonal contraceptives come with their own health risks - some of which will remain unknown.

- They also raise a host of medical questions concerning their mechanism of action (how the contraceptive actually works) and whether or not contraceptives serve as a form of abortion

2. Intrauterine Contraceptive Methods

- IUCD is a type of family planning method contraceptive method in which a flexible device is inserted through the virgina into the uterine cavity by a trained service provider. (World Health Organisation, 2018a)

3. Voluntary Surgical Contraceptives

- Surgical sterilization offers the most permanent form of contraception

- Female sterilization occurs by clipping the fallopian tubes which carry the eggs from the ovaries to the uterus

- Voluntary Surgical Contraception (VSC) type of family planning method includes female and male 
sterilization procedures that are intended to provide permanent contraception.

- Every client who chooses this method must do so voluntarily and is fully informed about the permanence of this method and the availability of alternative, long-acting, highly effective methods (Eranga 2015).

\section{Barrier Method of Contraceptive}

- Barrier family planning methods prevent the sperm from gaining access to the upper reproductive tract and making contact with the egg. These methods include; male and female condoms, Spermicides, Diaphragms, Cervical caps

- Meanwhile, barrier methods of contraception are hailed as the answer to international problems such as AIDS and other Sexually Transmitted Infections (Eranga 2015; Adelaide 2013).

5. Natural Family Planning Method

- It is called natural because it does not involve use of drug or device it is purely natural. The followings are the available natural family planning methods:

- $\quad$ Examples are; Withdrawal method (coitus interrupters); Safe period (rhythm method); Breastfeeding; Cervical mucus membrane, Basal body temperature (BBT) method (Etokidem et al. 2017).

\subsection{Use of Emergency Contraceptives in Nigeria}

Emergency contraception which is also known as "Morning After Pill," is a contraceptive or birth control method that can prevent pregnancy immediately after unprotected sexual intercourse or contraceptive failure, but prior to the beginning of any pregnancy (WorldHealthOrganisation 2018b). Some reasons for unprotected sex and contraceptive failure vary: such situation includes sexual assaults or rape, breaking of condom or inability to have access to a contraceptive method, unawareness of family planning (Sedgh et al. 2006). All these situations must therefore been given adequate consideration by Law and regulation in order to prevent the unpleasant consequences arising from unprotected sex like abortion, sexually transmitted diseases, criminality arising from frivolous childbirth and poor child upbringing, vagabondage, brigandage and population explosion. It is noteworthy that emergency contraception is not a regular method to control birth, it prevents pregnancy by delaying ovulation, inhibiting fertilization and or preventing implantation (PracticeBulletin 2015). Emergency contraception will not interrupt an established pregnancy and does not function as "abortion pill," i.e., it will not be effective if taken after a woman has conceived. Contraception, if taken within 72 hours of unprotected sexual intercourse can reduce the risk of pregnancy by $89 \%$ (Narzary 2009). This contraception is available in health care facility outlets.

The following information is to provide basic knowledge on Emergency Contraceptives as available in Nigeria.

- Emergency Contraceptives must be taken within 120 hours of intercourse, however, the sooner they are taken, the more effective they are in preventing pregnancy.

- Emergency Contraceptives should not be used on a regular basis (from month to month) Contraceptives because they are less effective contraceptives than other methods when used in such a manner.

- Emergency Contraceptives prevent between 75-95 percent of pregnancies that would otherwise have occurred (ClinicNigeria, 2013)

\subsection{Types of Emergency Contraceptives Pills and Dosage in Nigeria}

- Combined Oral Contraceptives( Ordinary Pills )

- Progestin-only Oral Contraceptives (E-pills): this is most commonly used (WorldHealthOrganisation 2018b)

\subsubsection{Combined Oral Contraceptive Emergency Contraceptives}

- contain hormones oestrogen and progesterone (75\% effective). Two standard dosage options are available (WorldHealthOrganisation 2018b):

- e.g. Eugynon and some other examples of $50 \mathrm{mcg}$ oestrogen pills: Two tablets to be taken as soon as possible after unprotected intercourse, but within 120 hours, repeat the same dose in 12 hours and total of four pills are required.

- $\quad$ e.g., Microgynon and some other examples of $30 \mathrm{mcg}$ oestrogen pills: Four tablets to be taken as soon as possible after unprotected intercourse, but within 120 hours. Repeat the same dose in 12 hours. A total of eight pills are required (Hirsch 2018)

7.2.2 Progestrine only Oral Contraceptive; E-Pill (commonly used) in Nigeria and World Wide

- Drugs in this category are dedicated emergency for sole purpose of preventing conception.

- More effective than combined Oral Contraceptive, 95\% effective. (WorldHealthOrganisation 2018b)

- Examples of brands available in Nigeria are Postinor2, Pregnon, Smart lady, ECee2, Truston2

Standard dosage is: check on the packet and follow procedure below:

- One $750 \mathrm{mcg}$ levonorgestrel pill to be taken as soon as possible after unprotected intercourse, but within 
120 hours. Repeat the same dose in 12 hours. A total of two pills are required.

- Two $750 \mathrm{mcg}$ levonorgestrel pills to be taken as a single dose as soon as possible after unprotected intercourse, but within 120 hours. This regimen is to be preferred because it easier to comply with the one-dose regimen compared to the two-dose regimen.

- Regular progestin-only pill (POP) may be used: 20 tablets taken within 120 hours after unprotected intercourse. Repeat the same dose in 12 hours. A total of $\mathbf{4 0}$ pills are required.

7.3 Advantages and Benefits of Emergency Contraceptives (Samra et al. 2017):

- It is safe, effective, and easy to use.

- No medical examination or pregnancy tests are necessary or required.

- It can be used at any time during the menstrual cycle

- Emergency Contraceptives (e- pills) are available in government, private, and NGO health facilities and over the counter at pharmacies.

7.4 Side Effect and Limitations of Emergency Contraceptives (Hirsch 2018)

- Emergency Contraceptives (e pills) are only effective Contraceptives if used within 120 hours of unprotected intercourse.

- They are not to be used as a regular method.

- $\quad$ Emergency Contraceptives (e- pills) do not prevent against STls, or HIV/ AIDS.

7.5 Categories of People who can use Emergency Contraceptives

Emergency Contraceptives (e- pills) are safe and appropriate for all women. Though some women might need additional monitoring or care.

- Sex took place without contraception, and you want to avoid pregnancy.

- A woman has run out of oral contraceptives, has missed two or more pills, or is more than four weeks late for her injections and had unprotected intercourse.

- A woman has had coerced sexual intercourse, such as rape.

- A condom has broken.

- An IUCD has come out of place.

Consider medical consultation before using emergency contraceptive if; (Omnia et al 2019)

- History of severe heart disease complications

- Woman with Angina Pectoris

- Women suffering from migraine

- Women with severe liver disease (including jaundice)

- Regular user of e-pill.

Those who should not use Emergency Contraceptives (e- pills): it should not be given to women who are known to be pregnant, but if Emergency Contraceptives (e- pills) are accidentally used by a woman who is pregnant, there is no known harm to the woman pregnancy when pregnancy is not at early stage (Narzary 2009).

\subsection{Traditional Position on the Use of Contraception}

Traditional methods of birth control is the practice, beliefs or customs handed down from one generation to another aimed at preventing pregnancy (Delano 2015). With respect to the practice of contraception there have been many methods which can be considered as the early forerunners of modern birth control and the basic concept of most of them still guides the idea of contraception today.

7.6.1 Regional Practices of Contraception in Ancient Times

Women at those days consume different types of seeds and leaves so that their chemical components would help to reduce fertility and these include eating castor oil seeds, ricunus seeds, willow leaves etc. While men also wore sheaths made of different materials from animal bladder, intestines, and other membranes over their penis to prevent pregnancy (Delano 2015).

Abortion was also employed as a means of contraception (Abiodun \& Balogun 2009). Women drank herbal preparations, saps from trees, or roots insertion of different herbs into the cervix with the sole aim of induced abortion. In South African, they practiced Coitus interruptus and Coitus reservatus (i.e. suppression of male orgasm and East-African women's abstains from sexual intercourse after menstruation (Amazigo et al. 1997). There were complications from this practice. In Nigeria, different traditional methods of family planning are being used (Etokidem et al. 2017). The traditional methods of contraception are divided into two groups. These are:

1. The Appliance Methods; and

2. The Non-Appliance 
1. The Appliance Methods involve specific preparations by herbalists or traditional healers and dispensed to individuals in form of specially prepared stew, herbal tea, or chewing stick, alternatively, the preparation could be taken, on behalf of the woman, by domestic animals or placed at a circular road as sacrifice to be consumed by the spirits to prevent conception (Delano 2015). On the one hand, injectable (scarification) could be administered by the herbalist incision on the supra pubic or spinal region of the male or female, followed by the application of specially prepared substance presumed to get absorbed through the blood stream as a long acting method of contraception. On the other hand, the use of barrier method: this consists of both physical and sperm killing agents, as well as the invisible barrier methods-wearing of enchanted waist-band, rings, amulets, snake/leopard skin (Delano 2015).

2. Delano (2015) further discover the Non-Appliance Method: this is self-administered method that includes abstinence from sex and avoiding sex during menstrual period. For examples: drinking of warm solution of salt, alum, vinegar, lemon, potassium or caustic soda. Abortion has also been used as a means of birth control (Tsui et al. 2010).

The reasons why couples rely on traditional methods are numerous. They include a lack of knowledge about modern methods and their modes of operation, the greater convenience of methods, fear of actual or perceived side effects of modern method, religious or cultural constraints, high lack of accessibility and high cost (Fagbamigbe et al. 2018; Williamson et al. 2009). The use of traditional contraceptives is mostly common among illiterate women (Etokidem et al. 2017).

7.6.2 Advantages of Traditional Methods of Family Planning and Use of Contraceptives. (Delano 2015)

i. Traditional Methods of family planning are cheaper in most cases than orthodox ones.

ii. It is more accessible to the populace.

iii. It enjoys wider acceptance among the people

iv. Consultation is not time consuming and impersonal

v. User enjoys good rapport with service provider and informed atmosphere.

7.6.3 Disadvantages of Traditional Methods of Family Planning and Use of Contraceptives (Delano 2015)

i. The efficacy of traditional methods lacks scientific proof and evidence.

ii. Traditional medicine lack precise dosage. However though, many practitioners today have introduced measurements into their drug administration.

iii. The unhygienic environment of most practitioners is a minus to the method as it may increase the spread of infection;

iv. Most barrier methods employed by traditional medicine increase the risk of pelvic inflammatory diseases and infertility

v. Some customs and practices may be dangerous and should be discourage as it can cause damage of the uterus or make a woman infertile.

7.6.4 Benefits of the Use of Contraceptives (Sonfield et al. 2013)

1. Contraception strengthens the marital bond in that it liberates sexual intercourse between partners from the fear of unwanted pregnancy (Mason et al. 2013).

2. A woman who uses contraception may have more opportunities to be able to work and engage in community-based activities because having fewer children may relieve some of the domestic burden inherent in raising a large family.

3. Contraception has been identified as an effective means of combating the problem of unwanted pregnancy and unsafe abortion.

4. It is equally an effective means of family planning and fertility control and therefore very important in promoting maternal and child health.

5. It has liberated them from uncontrolled large families;

6. This gives women the freedom to time their pregnancies to fit in with a more independent lifestyle.

7.6.5 Challenges of the Use of Contraceptives (Cleland et al. 2014)

Problems arise with many forms of contraception which should not be undertaken and not imposed. Some of this problem includes;

1. The long use of oral hormonally contraception with a high oestrogen content will predispose to intravascular thrombosis;

2. Risk increases where any form of hormonal contraceptive is combined with smoking

3. The use of third generation progestogen pills is higher that when using the earlier pills

4. The widely used interceptive methods may cause pelvic inflammation and permanent infertility.

5. The depot hormonal contraceptive preparations may cause menstrual disorder (Bromham, 1996). Insertion and removal also requires expertise (Blyth $v$ Bloomsbury Health Authority 1993).

6. The woman may be negatively perceived by the community for failing to produce as many children as expected. This occurs in Africa Countries, Nigeria is a good example. 
7. Young people and most people who reside in the rural areas often know little or have incorrect information about contraception and even when they can name contraceptives, they often do not know where to get them or how to use them.

8. The reason of fear of side effects and lack of adequate information or misinformation about contraception (Bromham 1996).

9. Some women did not use contraception as a result of objection from partner and family members.

10. Religion (Such as the Roman Catholic Church, see this as a form of termination, i.e. interfering with a fertilised ovum), and some people regard sex outside marriage as taboo (adultery) and Culturally, attitudes are extreme and premarital sex is considered a matter of great shame and a loss of family honor.

11. Marital splits and altered relationships may lead to renewed desire for offspring from the new unions, and reversal of sterilisation does not guarantee conception.

12. The inaccessibility of contraception will devast social, economic, public health with the consequences of inability to protect themselves from HIV and other sexual transmitted infection.

13. Lack of use of contraceptives will cause inability to control fertility and reproduction.

7.6.6 Other Challenges with the Use of Contraceptives

Many women dislike the idea of ingesting artificial hormones or of devices implanted in their bodies (Hall et al. 2010). Increasingly, the effects of contraceptives on women's health are becoming more evident and the side effects of use of hormonal contraceptives are enormous, such as: rashes, loss of libido, discoloration of the skin (melasma/chloasma), changes in weight or appetite, nausea, vomiting, migraines, mood changes (including depression), aggravation of varicose veins, gastrointestinal symptoms (pain, cramps, bloating), spotting, vaginitis (yeast infection), vitamin deficiencies, water retention, vision impairment, liver malfunction (jaundice). Furthermore, numerous studies show increased risk of cancer and increased risk of blood clots resulting from the use of hormonal contraceptives (Batres et al. 2018; Goldstuck \& Kluge 2017; Shukla et al. 2017).

Thousands of lawsuits have been filed in recent years against manufacturers of various birth control pills for serious health complications suffered such as: Heart attack, Stroke, Deep vein thrombosis (blood clots in legs), pulmonary embolism (blockages in the lungs), gallbladder disease (Tighe 2018). Likewise, thousands of women have filed claims against the manufacturers of the Mirena IUD (intrauterine devices) for serious side effects (Tighe 2018). In general IUDs increase risk of: Ectopic pregnancy (tubal pregnancy), Pelvic inflammatory disease, Abnormal bleeding, Infection, Displacement of the device, which can lead to serious complications (Wayne \& Jerry 2019). Hundreds of women have also reported adverse reactions to the assure sterilization procedure, with at least 91 women having to undergo a hysterectomy as a result of damages (Moorman et al. 2012).

Since abortion is illegal in Nigeria (unless medically recommended to save a mother's life), many abortions are carried out secretly, and often in an unsafe environment (Abiodun \& Balogun 2009). The leading contributory factor to unwanted pregnancy in Nigeria is low contraceptive usage (Wang \& Cao 2019; Fayehun, 2017). The current prevalence rate for contraceptive use in Nigeria is approximately $11 \%-13 \%$ (Monjok et al. 2010). This rate is very low in spite of the high rate of sexual activity (the average age of sexual debut ranged between 12 and 20 years, with a mean age of $16+1.2$ years) and widespread awareness of the various contraceptive methods (ranging between $29 \%$ and $69 \%$ depending on the method) among Nigerian adolescents and youths (UnitedNations 2011).

It has also been noted that some women use abortion as a means of child-spacing instead of using modern contraception, due to fear of future infertility (Otoide et al. 2001). This implies that many intuited that the adverse effect of modern contraceptives on fertility to be continuous and prolonged, while abortion was seen as an immediate solution to an unplanned pregnancy. Also, some women fail to use contraception as a result of objection from partner and family members (Fagbamigbe et al. 2018). Meanwhile, the use of contraceptive methods is not exclusively to unmarried/young women, as a significant number of older/married women in the reproductive age group also sought abortion (Oye-Adeniran et al. 2004a). This is a reflection of low contraceptive use among the older/married women who desired child-spacing and limited family size in view of present economic hardship in Nigeria (Oye-Adeniran et al. 2004b). Another reason for ineffective use of contraceptive is the fear of side effects, lack of adequate information/misinformation, objections from their partners, conflicts with their religious beliefs, objections from family members, not thinking about using contraceptives, not having sexual intercourse to have baby, and unplanned sexual intercourse (National Population Commission, 2011). All these reasons depicted a basic problem, which is lack of proper education on contraception.

The observation that a significant proportion of women opting for repeat induced abortion were youths (1524 years) and the fact that a woman presenting for second- or higher-order repeat induced abortion is more likely to be single than married are worrisome (Kavanaugh et al. 2011). This is born out of the fact that the level of knowledge and awareness of contraception is high among the youths (Alano \& Hanson 2018; Bankole \& 
Onasote, 2017; Bello et al. 2016; Adewole et al. 2002). But paradoxically, contraceptive utilization rate is low among the youths due to the gap in communication between health providers and unmarried youths regarding their rights to privacy and confidentiality (Sychareun 2004). Besides, the study conducted by Adewole et al. (2002) revealed a high level of awareness among the participants and despite that, only $21.5 \%$ of 1,839 One thousand, eight hundred and thirty three tried contraception after the last abortion, showing a great gap between awareness and usage. This indicates that the knowledge acquired does not necessarily translate into attitudinal change where contraception usage is concerned.

\subsection{Suggested Solutions to the Indiscriminate and Improper Use of Contraceptives in Nigeria}

1. Alternatives to sterilisation should be considered and patients counseled about the irreversible nature of sterilisation.

2. A special need exists for their education about the availability of different choices of contraceptive methods so that they can be empowered to control their fertility according to their needs.

3. This relies on abstinence from intercourse at the most fertile time (around ovulation) of the menstrual cycle.

4. Medical indications can override many prohibitions.

\subsection{Conclusion}

This paper is an overview of what contraception entails but, focused more on the Nigerian perspectives regarding the factors affecting knowledge and use of contraceptives, pitfalls arising from the unregulated use of contraceptives, wrong use and the possible means of overcoming the barriers of lack of knowledge.

Based on the literature surveyed, knowledge and use of contraceptives is low in Nigeria as a result of absence of proper education on the subject matter and majority with high knowledge of contraception also failed to use the modern methods due to lack of clarity of knowledge. Unfortunately, 1 of 9 global maternal deaths occurred in Nigeria (World Children Report 2009). Hence, if clarity of contraceptive knowledge remains a bone of contention among women and young girls then the increase in the incidence of unwanted pregnancies will be alarming. Thereby jeopardizing the economic, social and well being of women especially those who are indisposed to standard medical care, will further increase population and consequently aggravate the level of poverty in the country.

This review observed that having knowledge of various contraceptive methods has a great effect on its use and age is not a determinant of education nor exposure but sound education on use / benefits of contraceptive. Thus, diverse educational measures should be adopted to educate both rural and urban women on modern contraceptive methods as such knowledge is wanting. Besides, enlightenment campaign and other forms of psycho-education targeted at women and their reproductive needs may help build their self-confidence in the ability to use contraceptives as opposed to their contradictory religious and cultural belief of contraception. More effort is therefore expected from government agencies, Health care Non-governmental Organisations, the Nigerian legislature and ministries of health and justice in the quest for better enlightenment, enabling environment and most especially in the promulgation of laws, regulation and policies geared towards encouraging women on correct and proper use of birth control methods on one hand, and implementing same on the other hand. Nevertheless, increase in use of modern contraceptive method requires community-wide, multifaceted interventions and the combined provision of information, life skills, support and access to youthfriendly services. Therefore, negative perceptions of modern contraceptive methods should be disabused and the dual role of condoms for contraception and STI prevention should be exploited, despite the enumerated challenges involved, as the advantages of contraceptive use is much more than its disadvantages.

\section{Recommendations}

i. Public enlightenment on contraception should start from antenatal and gynaecological clinics. This can be extended to other outpatient clinics which men are part of, so that the information on contraception will spread to as many people as possible. This will reduce the magnitude of misconception/misinformation on contraception to a minimum level and increase contraceptive use.

ii. The speedy enactment of a robust, comprehensive and comprehensive National Reproductive Health Law that would amongst other things regulate the use of contraceptives in women in Nigeria is urgently desired.

iii. Incorporation of post-abortion contraceptive counseling as part of comprehensive abortion care. This should be done by training health care providers in abortion care.

iv. Intensive advocacy for liberalization of abortion policy in Nigeria from being restrictive is mandatory in order to provide a supportive environment for both health care providers and patients.

v. Improvement of contraceptive use among youths can be done by providing adolescent-friendly sexual education as well as reproductive and contraceptive services. 
vi. There is also a need to translate high contraceptive awareness to an increased use in order to bridge the large gap of unmet need. There is a need to throw light on misinformation about contraception. A significant component of any family planning program for Nigeria would have to be concentrated on community health education to reduce misconceptions about the side effects of modern contraceptives, which is the most common reason for nonuse of modern contraceptives in Nigeria. Another component would be the involvement of men in family planning and use of the radio for information dissemination.

vii. Government should provide more Family Planning clinic to make access to health facilities easier specifically in the rural areas.

viii. Husband/Men should be encouraged to follow their wives to Family Planning clinic for ease of contraceptive method selection and change of attitude towards contraception.

\section{Acknowledgement}

The authors thank Professor Olarinde E.S, Dr. Olusegun Olaitan and Mr. Alade Babatope, for their moral supports in the course of drafting the paper.

\section{References}

Abiodun, O. M \& Balogun, O.R. (2009), "Sexual activity and Contraceptive use among young Female Students of Tertiary Educational Institutions in Ilorin, Nigeria". 79(2) Contraception, 146 - 149.

Adegbola, O., Habeebu-Adeyemi, F. M. (2016), "The Infuence of Male Partners on Contraceptive Usage in SubSahra Africa-Lagos Experience". 13(3), Journal of Clinical Science, 112-116.

Adeleke, A, Omoregie, P, \& Edoni, E. (2014), "Male involvement in family planning: Challenges and way Forward". 2014, International Journal of Population Research, 1 - 9.

Adelaide (2013), "Contraception-bioethical issues centre for bioethics and culture". Accessed 9 June 2019 from: http://www.bioethics.org.au/Resources/Resources\%20Topics/Contraception.html

Adewole, L. F., Oye-Adediran, B. A., Nwere, N., Oladokun, A., Gbadegesin, A. \& Babarinsa L. A. (2002), "Contraceptive usage among abortion seekers in Nigeria". 21(2), West African Journal of Medicine, 112 114.

Ahmed, S, Liu, L.Q. \& Tsui, A. O. (2012), "Maternal deaths averted by contraceptive use: an analysis of 172 countries". 380(9837), The Lancet, 111 - 125.

Aina-Pelemo, A. D., Mehanathan, M. C. Kulshrestha, P. (2018), "Sexual Harassment at Workplace: Judicial Impact in Nigeria and India". 4(2), Indian Journal of Law and Human Behaviour, 211 - 225.

Aina-Pelemo, A. \& Saluja, S. (2018), "Comparative Analysis of Sex-Selection in Nigeria and India". 4(6), International Journal of Humanities and Social Science Studies, 70-88.

Alano, A., \& Hanson, L. (2018), "Women's perception about contraceptive use benefits towards empowerment: A phenomenological study in Southern Ethiopia". 13(9), PLoS ONE, e0203432.

Amazigo, U., Silva, N., Kaufman, J. \& Obikeze, D. S. (1997), "Sexual activity and contraceptive knowledge and use among in-school adolescents in Nigeria". (23)1, International Family Planning Perspectives, 28 - 33.

Babalola, S., John, N., Ajao, B., Speizer, I. (2015), "Ideation and intention to use contraceptives in Kenya and Nigeria”. (33)8, Demographic Research. 211 - 238.

Bankole, O. M. \& Onasote, O. M. (2017), "Awareness and sources of contraception information among female university students in Nigeria”. Information Development, 33(2), 199-209.

Batres, C., Porcheron, A., Kaminski, G., Courreges, S., Morizot, F. \& Russell, R. (2018), "Evidence that the Hormonal Contraceptive Pill is Associated with Cosmetic Habits". 9, Frontiers in Psychology, 1459.

Bello, O. O., Oluwasola, T. A. \& Bello, F. A. (2016), "Awareness and practice of dual contraception among female tertiary institution students in Ibadan, Nigeria”. 2016, Open Access Journal of Contraception, 103115.

Blyth v Bloomsbury Health Authority, (1993) 4 Med LR 151

Bromham, DR. (1996), “Contraceptive implants". 312(7046), British Medical Journal, 1555-1556.

Chakrabartty, S., Zhang, H., Dong, X. \& Alfred, M. O. (2017), "Benefits of Oral Contraceptive Pill Pretreatment in Endometriosis for IVF/ICSI-ET: A Retrospective Cohort Study”. 6(8), International Current Pharmaceutical Journal, 45-48.

Cleland, J., Conde-Agudelo, A., Peterson, H., Ross, J. \& Tsui, A. (2012), "Contraception and health". The Lancet, 380(9837), $149-156$.

Cleland, J., Harbison, S. \& Shah, I. H. (2014), "Unmet need for contraception: issues and challenges". 45(2), Studies in Family Planning, 105-122.

Clinic Nigeria (2013), "Emergency contraceptives Nigeria, family planning and contraceptives types and methods available in Nigeria". Accessed 17 June 2019. From: <http://clinicnigeria.blogspot.com/>

Dayal, M. \& Barnhart, K. T. (2002), "Non-Contraceptive Benefits and Therapeutic Uses of the Oral Contraceptive Pill”. 19(4), Seminars in Reproductive Medicine, 295-303. 
Delano, G. E. (2015), “Traditional Method of Birth Control: Desired or Not, Good or Bad?” Online, Accessed from: <https://nigerianobservernews.com/2015/05/traditional-method-of-birth-control-desired-or-not-goodor-bad/> 9 June 2019.

Drife, J. (1991), "Benefits and Risks of Oral Contraceptives”. 6, Advances in Contraception Supply, 15-25.

Eniojukan, J. F., Ofulue, I. \& Okinedo, P. O. (2015), "Knowledge, Perception and Practice of Contraception among Staff and Students in a University Community in Delta State, Nigeria". 2347-9442 (2013-2018, Pharmaceutical and Biosciences Journal, 1.

Eranga, I. (2015), "Contraceptive methods and options in Nigeria" the Nigerian Observer that the people may know”. $\quad$ Accessed $17 \quad$ June $\quad 2019$ from: $<$ http//www/contraceptive/methods/and/options/in/Nigeria/Nigerian/observer/>

Etokidem, A. J. Ndifon, W. \& Asuquo, E. F. (2017), Family Planning Practices of Rural Community Dwellers in Cross-River State, Nigeria. 20(6), Nigerian Journal of Clinical Practice, 707-715.

Fagbamigbe, A. F., Afolabi, R. F. \& Idemudia, E. S. (2018), "Demand and Unmet Needs of Contraception among Sexually Active In-Union Women in Nigeria: Distribution, Associated Characteristics, Barriers, and Program Implications". 8(1), Sage Open, 1-11.

Fayehun, F. (2017), "Contraceptive use in Nigeria is incredibly low. This could be why". Online, Accessed from: $<$ https://www.iol.co.za/news/africa/contraceptive-use-in-nigeria-is-incredibly-low-this-could-be-why10502316>9 June 2019.

Goldstuck, N. D. \& Kluge. J. (2017), "Fourth Generation Oral Contraception: A new Era in Safety". 27(1), Obstetrics and Gynecology Forum, 25-28.

Guttmacher, A. (1981), "Teenage pregnancy: The Problem that hasn't gone away". New York: Allan Guttmacher Institute.

Hall, K. S., White, K. O., Reame, N. \& Westhoff, C. (2010), "Studying the Use of Oral Contraception: A Review of Measurement Approaches". 19(12), Journal of Women's Health, 2203-2210.

Hirsch, L. (2018), "Emergency Contraception". (TeensHealth). Accessed 17 June 2019, from: https://kidshealth.org/en/teens/contraception-emergency.html

Holland, K. (2017), "Emergency Contraception: Possible Side Effects". (healthline), Accessed June 132019 , from: https://www.healthline.com/health/emergency-contraception/possible-side-effects

Hubacher, D. \& Trussell, J. (2015), A Definition of Modern Contraceptive Methods. 92(5), An International Reproductive Health Journal Contraception, 420-421.

Idoko, C. A., Omotosho, B., Anyaka, C., Udo, K., Ezenwosu, O. Nwobi, E., Ezeoke, U., Obi, I., Ekwueme, O., Okeke, C., Obienu, C. \& Orakwue, I. (2018), "Opinion and use of contraceptives among medical students of the University of Nigeria, Enugu campus". 18(3), African Health Science, 637-644.

Inal, Z. O., Inal, H. A., Kucukkendirci, H., Oruc, A. S. \& Gunenc,O. (2017), "The level of using family planning methods and factors that influence the preference of methods in the Konya-Meram area". 18(2), Journal of Turkish German Gynaecology Association, 72-76.

Jensen, J. \& Speroff, L. (2001), "Health Benefits of Oral Contraceptives". 27(4), Obstetrics and Gynaecology Clinics of North America, 705-721.

Jin, J. (2014), “Oral Contraceptives”. 311(3), JAMA Patient Page, 321.

Johannes, H., Bentz, E., Ott, J. \& Tempfer, C. B. (2008), "Non-Contraceptive Benefits of Oral Contraceptives". 9(13), Expert Opinion on Pharmacotherapy, 2317-2325.

Johnson, S., Pion, C. \& Jennings, V. (2013), "Current Methods and Attitudes of Women towards Contraception in Europe and America”. 10(7), Reproductive Health, 1.

Kavanaugh, M. L, \& Anderson, R. M. (2013), "Contraception and Beyond: The Health Benefits of Services Provided at Family Planning Centers". 3(2), Open Journal of Depression, 1.

Kavanaugh, M. L., Carlin, E. E., \& Jones, R. K. (2011), "Patients' attitudes and experiences related to receiving contraception during abortion care". 84(6), Contraception, 585-593.

Ladan, M. T. (2006), "Review of Existing Reproductive Health Policies and Legislations in Nigeria". A paper presented at a one day stakeholders forum on reproductive health in Nigeria on the $20^{\text {th }}$ April 2006. Accessed from < http://www.gamji.com/article5000/news5997.html $>9$ June 2019.

Mason, J. K., Mason, L. G. \& McCall, R. (2013), Smith's Law and Medical Ethics (9 ${ }^{\text {th }}$ ed.). Oxford University Press.

Monjok, E., Smesyn, A., Ekabua, J. E. \& Essien, E. J. (2010), “Contraceptive practices in Nigeria: literature review and recommendation for future policy decisions". 1 Open Access Journal of Contraception, 9-22.

Moorman, P. G., Myers, E. R., Schildkaurt, J. M., Iversen, E. S, Wang, F. \& Warren, N. (2012), "Effect of Hysterectomy with ovarian preservation on ovarian function" 118(6) Obstetrics Gynecology, 1271-1279

Moreland, S., \& Talbird, S. (2006), "Achieving the Millennium Development Goals: The Contribution of Fulfilling the Unmet Need for Family Planning". Washington, DC: Constella Futures, POLICY Project. (Online). Accessed 17 June 2019, from: 
$<$ http://www.healthpolicyplus.com/archive/ns/pubs/hpi/MDGMaster\%209\%2012\%2006\%20FINAL.pdf> 9 June, 2019.

Narzary, P. K. (2009), "Knowledge and Use of Contraception among Currently Married Adolescent Women in India". 3(1), Studies on Home Community Science, 43-49.

National Population Commission. (2011), "Nigeria 2008: results from the demographic and health survey (2011). National population Commission; ICF Macro". 42(1) Studies in Family Planning, 51-56.

Nsubuga, H., Sekandi, J. N., Sempeera, H. \& Makumbi, F. E. (2016), Contraceptive Use, Knowledge, Attitude, Perceptions and Sexual Behaviour among Female University Students in Uganda: A Cross-Sectional Survey. 16(6), BMC Women's Health, 1.

Osborn, C. O. (2019), "Hysterectomy side effects to consider" Accessed 13 June 2019 from: https://www.healthline.com/health/hysterectomy-side-effects

Otoide, V. O., Oronsaye, F. \& Okonofua, F. E. (2001), "Why Nigerian adolescents seek abortion rather than contraception: Evidence from Focus-group Discussions". 27(2), International Family Planning Perspectives, 77 - 81.

Oye-Adeniran, B. A., Adewole, I. F., Umoh, A. V., Ekanem, E. E., Gbadegesin, A. \& Iwere, N. (2004), "Community-based survey of unwanted pregnancy in southwestern Nigeria". 8(3), African Journal of Reproductive Health, 103 - 115.

Oye-Adeniran, B. A., Adewole, I. F., Odeyemi, K. A., Ekanem, E. E. \& Umoh, A. V. (2005), “Contraceptive prevalence among young women in Nigeria”. 25(2), Journal of Obstetrics and Gynaecology, 182 - 185.

Peterson, H. B., Darmstadt, G. L. \& Bongaarts, J. (2013), "Meeting the unmet need for family planning: now is the time". 381(9879), The Lancet, 1696 - 1699.

Practice Bulletin (2015), "Emergency contraception”. American College of Obstetricians and Gynecologists, 152(126), e1-11.

R (Smeaton) v Secretary of State for Health [2002]2 FCR 193 68, 69.

Samra, O. M., Cowan, B. D., Talavera, F. \& Shulman, L. P. (2017), "Emergency Contraception" (emedicinehealth), Accessed 17 June 2019, from: $<$ https://www.emedicinehealth.com/emergency_contraception/article_em.htm\#what_is_emergency_contrac eption>

Schindler, A. E. (2013), "Non-Contraceptive Benefits of Oral Hormonal Contraceptives". 11(1), International Journal of Endocrinology, 41-47.

Sedgh, G., Akinrinola, B., Oye-Adediran, B., Adewole, I. F., Singh, S., \& Hussain, R. (2006), "Unwanted pregnancy and associated factors among Nigerian women". 32(4), International Perspectives on Sexual and Reproductive Health, 175-184.

Shukla, A., Jamwal, R. \& Bala, J. (2017). "Adverse effect of combined oral contraceptive pills". 10(1), Asian Journal of Pharmaceutical and Clinical Research, 17-21.

Sonfield, A., Hasstedt, K., Kavanaugh, M. L. \& Anderson, R. (2013), "The social and economic benefits of women's ability to determine whether and when to have children". (Report), New York: Guttmacher Institute.

Sychareun, V. (2004) "Meeting the contraceptive needs of unmarried young people: attitudes of formal and informal sector providers in vientiane municipality, Lao PDR". 12(23), Reproductive Health Matters, 155 165.

Tighe, C. (2018), "Hundreds of patients are claiming the mirena IUD causes a neurological disorder-but experts says more reseacrh is needed". Accessed 6 May 2019 (Rewire News) from: https://rewire.news/article/2018/12/04/hundreds-of-patients-are-claiming-the-mirena-iud-causes-aneurological-disorder-but-experts-say-more-research-is-needed/

Tsui, A. O., Mcdonald-Mosley, R. \& Burke, A. E. (2010), "Family planning and the burden of unintended pregnancies”. 32(1) Epidemiologic Reviews, 152 - 174.

Tyrer, L. (1999), "Introduction of the pill and its impact". 59(1), Contraceptive Supply, 11S-16S.

United Nations and Department of Economic and Social Affairs-Population Division. (2011), "World Contraceptive Use". Website, Accessed from: $<$ http://www.un.org/esa/population/publications/contraceptive2011/wallchart_front.pdf $>9$ June 2019.

Uzoma, P. O. (2016), "Reproductive Health and the Right to Contraception in Nigeria: The Way Forward". 57(6), NIALS Journal of Health Law and Policy Maiden, 307-313.

Uzoukwu v Ezeonu (1991), NWLR 708 (Pt. 200) 764-778.

Wang, C. \& Cao, H. (2019), Persisting Regional Disparities in Modern Contraceptive Use and Unmet Need for Contraception among Nigerian Women". 2019, BioMed Research International, 1-9.

Wayne, B. \& Jerry, R. B. (2019), "Birth control types (effectiveness and side effects". (emedicinehealth), $\begin{array}{llll}\text { Accessed } & 13 & 2019 & \text { June }\end{array}$ https://www.emedicinehealth.com/birth_control_overview/article_em.htm\#what_facts_should_i_know_abo 
ut birth control

Williamson, L. M., Parkes, A., Wight, D., Petticrew, M. \& Hart, G. J. (2009), "Limits to Modern Contraceptive use among Young Women in Developing Countries: a Systematic Review of Qualitative Research". 6(3), Reproductive Health, 1-12.

World Health Organisation (2018a), "Fact Sheet on Family Planning/Contraception". Online, Accessed 9 June 2019, from: $<$ https://www.who.int $>$ news $>$ factsheet $>$ detail.html $>$

World Health Organisation (2018b), "Emergency Contraception". Accessed 17 June 2019 from: $<$ https://www.who.int/news-room/fact-sheets/detail/emergency-contraception> 